\title{
Sex-specific mortality of European shags after the Prestige oil spill: demographic implications for the recovery of colonies
}

\author{
Alejandro Martínez-Abraín ${ }^{1, *}$, Alberto Velando ${ }^{2}$, Daniel Oro $^{1}$, Meritxell Genovart ${ }^{1,4}$, \\ Cati Gerique $^{3}$, Miguel Angel Bartolomé ${ }^{3}$, Elena Villuendas ${ }^{3}$, Blanca Sarzo ${ }^{3}$ \\ ${ }^{1}$ IMEDEA (CSIC-UIB), C/Miquel Marqués 21, 07190 Esporles, Majorca, Spain \\ ${ }^{2}$ Departamento de Ecoloxía e Bioloxía Animal, Facultade de Ciencias, Campus Lagoas-Marconsende, \\ Universidade de Vigo, 36310 Vigo, Spain \\ ${ }^{3}$ Centro de recuperación de fauna Granja de El Saler, Conselleria de Territorio y Vivienda, Avda. de los Pinares 106 , \\ El Saler, 46012 Valencia, Spain \\ ${ }^{4}$ Sezione di Biologia Evolutiva, Dipartimento di Biología, Universita' di Ferrara, Via Borsari 46, 44100 Ferrara, Italy
}

\begin{abstract}
Oil spills are extreme environmental perturbations (i.e. ecological catastrophes) affecting marine food webs and especially top predators, in which effects are likely amplified. As such, seabirds suffer from direct mortality and food depletion, with potentially important consequences for the population growth rate and probability of extinction. However, little is known about the effects of sex-skewed mortality (due to sex spatio-temporal differences in at-sea distribution) in seabird population dynamics. We analyzed the mortality of European shags Phalacrocorax aristotelis after the Prestige oil spill and its effects on breeding colonies in Galicia (southwest North Atlantic). Most adults found dead were females (85\%). The year after the spill, Monte Carlo simulations of population trajectories predicted a reduction of $11 \%$ in the number of breeding pairs when skewed mortality was considered, and a lower rate $(8 \%)$ when assuming random sex distribution of adult mortality. The further reduction predicted with the sex-biased mortality was probably the result of unmated adults unable to reproduce. This difference, although slight, is a concern for conservation owing that the colonies studied were already showing a $5 \%$ annual decline due to other factors also related to human activities.
\end{abstract}

KEY WORDS: Skewed mortality $\cdot$ Sex $\cdot$ Oil spills $\cdot$ Demographic consequences $\cdot$ Prestige $\cdot$ Shags

\section{INTRODUCTION}

In many animal species, sexual differences in the susceptibility to adverse conditions and ecological catastrophes are expected due to sexual differences in the foraging and reproductive behaviour. This is particularly relevant among birds, where it is common for males and females to differ in their choice of foraging locations (Lewis et al. 2002, Forero et al. 2005) and the arrival time to breeding areas (Morbey \& Ydenberg 2001). However, population implications have been little investigated even though it is known that life history traits may vary between sexes (Stearns 1992), that sex-specific mortality caused by humans can exist (e.g. Weimerskirch \& Jouventin 1987) and that alterations of the sex ratio on adults can potentially have an impact on growth rates in both monogamous and non-monogamous species (Legendre et al. 1999, Brook et al. 2000). Oil spills are events that can potentially have dramatic effects on marine bird populations, and can be an interesting biological model to explore the demographic consequences of sex-specific vulnerability.

Oils spills are catastrophic events, and because they can endanger populations that are otherwise thriving, they can be analyzed as part of the general phenomenon of environmental stochasticity. This is especially 
true in small populations where massive mortality can lead to extinction or to inverse density dependence consequences such as Allee effects (Engen et al. 2003). More specifically, oil spills are known to be a major cause of mortality in seabirds (e.g. Rice et al. 1996), although, surprisingly, the potential role of oil spills as selective agents of sex-specific mortality (Heubeck et al. 2003) and their demographic consequences have not been previously considered.

On 13 November 2002, the oil tanker Prestige started to spill heavy bunker oil in the waters off the coasts of Galicia (NW of the Iberian Peninsula). During the following months the wreck released about 60000 tonnes of oil, making the Prestige oil spill the largest perturbation of its type in Europe (e.g. García-Pérez 2003). During this oil spill most of the affected seabirds were wintering juvenile auks (Camphuysen et al. 2002, García et al. 2003). However, hundreds of resident European shags Phalacrocorax aristotelis also perished (García et al. 2003). The European shag, a typical nearshore seabird, is found throughout the area affected by the Prestige oil spill (see Velando et al. 1999). It is a footpropelled pursuit-diver, feeding predominantly on pelagic and benthic fish, typically within a radius of $20 \mathrm{~km}$ around the breeding colonies (Velando \& Freire 1999). Although the spill occurred 3 mo before the onset of shag breeding, this species is largely sedentary and shags remain around breeding colonies throughout the year (Velando \& Alvarez 2004).

We were interested in testing whether the oil spill could have selectively caused a differential mortality of shags by age or sex, and to explore the demographic consequences of potentially skewed mortality on the recovery of colonies (Engen et al. 2003). Regarding sex, it is commonly assumed that population dynamics are determined by the female rates of adult survival and fecundity (vital rates) (Brook et al. 2000). However, if vital rates of males and females are different both sexes should be taken into account separately to understand population responses. This is especially true in purely monogamous mating systems where a male-skewed mortality, as well as a female-skewed one, may have a substantial negative effect on reproduction because a fraction of the females may be left unmated (Caswell 2001). Conversely, in purely polygamous systems demographic problems arise mainly with a lack of females to fecundate, and very low densities of males, up to a threshold, can occur with little effect on the fecundity of females (Caughley 1977).

Shags are mainly monogamous, with 3 to $5 \%$ polygyny (Cramp \& Simmons 1977), and consequently a sex-skewed mortality could have important demographic effects. In addition, shags are typically longlived birds and consequently population sizes are dramatically affected by changes in adult mortality
(Martínez-Abraín et al. 2001, Velando \& Freire 2002). In the present study we explored the differential mortality by sex of adult and sub-adult shags after the Prestige oil spill, and modelled how the results could influence the future recovery of colonies.

\section{MATERIALS AND METHODS}

Study area. The study area was located on the southern coast of Galicia, SW North Atlantic, corresponding to the area affected by the spill of $60000 \mathrm{t}$ of heavy fuel oil after the Prestige wreck (Fig. 1). This area hosts 2 large European shag colonies (Cíes and Ons Islands) of the Atlantic subspecies that sum up to ca. $2 \%$ of the world population of the species (Velando et al. 1999), located at their southernmost limit of distribution.

Sexing shags. All shag carcasses were collected between December 2002 and July 2003 by volunteers and staff of the regional environmental agency and kept frozen in facilities of the regional government of Galicia (Xunta de Galicia). During the summer of 2004 a sample of 137 shag corpses from the Prestige oil spill were thawed $(<24 \mathrm{~h})$ to be sexed through direct inspection of gonads. Most shags were successfully sexed by direct visual inspection $(\mathrm{n}=114)$. From corpses for which visual identification of gonads was not possible, owing to its advanced stage of decomposition ( $\mathrm{n}=23)$, a small sample of muscle tissue was taken to be molecularly sexed. Using polymerase chain reaction, we amplified CHD genes and results were observed in a $3 \%$ agarose gel stained with ethydium bromide, detecting 1 band in males and 2 bands in females. Only 7 shags could not be sexed by either method. Age was determined for all

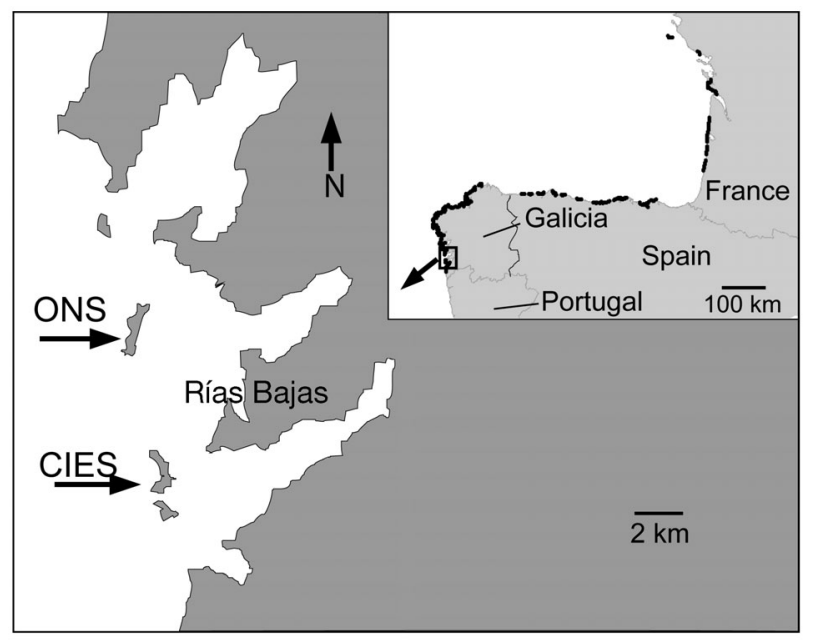

Fig. 1. Location of the 2 main shag colonies in the Rías Bajas area (Cíes Islands [CIES] and Ons Islands [ONS]) affected by the Prestige oil spill along the coast of Galicia (NW Spain). Black dots along the shoreline in the inset map mark where oil came ashore 
birds by plumage characteristics, except for 8 birds owing to the abundant oil covering their plumage, and classified as either adults (birds with complete back plumage) or immature birds (birds still with some whitish or brownish plumage).

Data analysis. Deviations in the sex ratio from the 1:1 ratio (i.e. $50 \%$ males and $50 \%$ females), and differences in age composition (50\% adults and $50 \%$ immature birds), were studied by means of contingency tables together with the chi-square statistics with Yate's correction for continuity. To study the interaction between sex ratio and age we used a logistic regression model.

Population modelling. We modelled the population dynamics of shags breeding at Rías Bajas (Cíes and Ons islands; Fig. 1) using a 2-sex matrix model (Caswell 2001) with 4 age classes (chicks, first year, second year and adults). The demographic parameters used in this model included the reproductive success, survival and recruitment estimated during the period 1994-1997 (for details see Velando \& Freire 2002, Velando et al. 2005a). A balanced chick sex-ratio was assumed in the model (Velando et al. 2002). The population was modelled including 2 logic functions, where reproductive pairs were dependent on the minimum number of males and females available (i.e. the number of possible matings), and adults were assumed to mate prior to second-year birds. The age-distribution before the Prestige oil spill was estimated based on age population structure obtained from a previous matrix model (Velando \& Freire 2002) and population estimates in 1994 (Velando et al. 1999).

Simulations by stochastic models were used to investigate population trajectory under 3 different scenarios: (1) with no mortality, (2) with the estimated differential mortality by age and sex, and (3) with the estimated differential mortality by age, but assuming no sex-skewed mortality. Probabilistic binomial distributions of demographic parameters were applied to add demographic stochasticity, which assigned population sizes to integer values. For environmental stochasticity, each demographic parameter was randomly selected from a Gaussian distribution generated from average and variance estimates obtained in the field during pre-spill years (Velando \& Freire 2002). Monte Carlo simulations were used to draw population trajectories (1000 runs) over time $(10 \mathrm{yr})$ and to estimate annual population growth rates from the estimated number of breeding pairs with bounded error probability.

\section{RESULTS}

A total of 130 European shags Phalcrocorax aristotelis were successfully sexed, although sex and age were determined for a sub-sample of only 122 individuals. Most birds in our sample $(62 \%)$ were immature whereas the remaining birds $(38 \%)$ were adults, $\left(\chi^{2}=\right.$ $3.26 ; \mathrm{df}=1 ; \mathrm{p}=0.07 ; \mathrm{n}=122)$. Results showed unequivocally that the male to female ratio of immature shag corpses was close to the $1: 1$ ratio $\left(\chi^{2}=0.42 ; \mathrm{df}=1 ; \mathrm{p}=\right.$ $0.52 ; \mathrm{n}=76$ ). However, the sex-ratio of adult shags was clearly skewed towards females $\left(\chi^{2}=11.13 ; \mathrm{df}=1 ; \mathrm{p}=\right.$ $0.001 ; \mathrm{n}=46$ ). More specifically, ca. $85 \%$ of the adult birds in our sample were females (Fig. 2). Our logistic regression model showed a statistically significant effect of age on the sex of shags $(\mathrm{r}=-0.49 ; \mathrm{B}=-1.45$; Wald statistic $=9.50 ; \mathrm{df}=1 ; \mathrm{p}=0.002)$. $\mathrm{B}$ is the maximum likelihood estimate of the coefficient of the parameter of the logical model.

Simulations indicated that the observed femaleskewed mortality should involve a reduction of breeding pairs, especially in the first 2 yr (Fig. 3). In 2003 (breeding season immediately following the Prestige oil spill), population modelling predicted a reduction of $11 \%$ in the number of breeding pairs when observed skewed mortality was considered, but a lower rate $(8 \%)$ when assuming random sex distribution of adult mortality. Thus, when sex-specific mortality was included in the models, annual growth was expected to

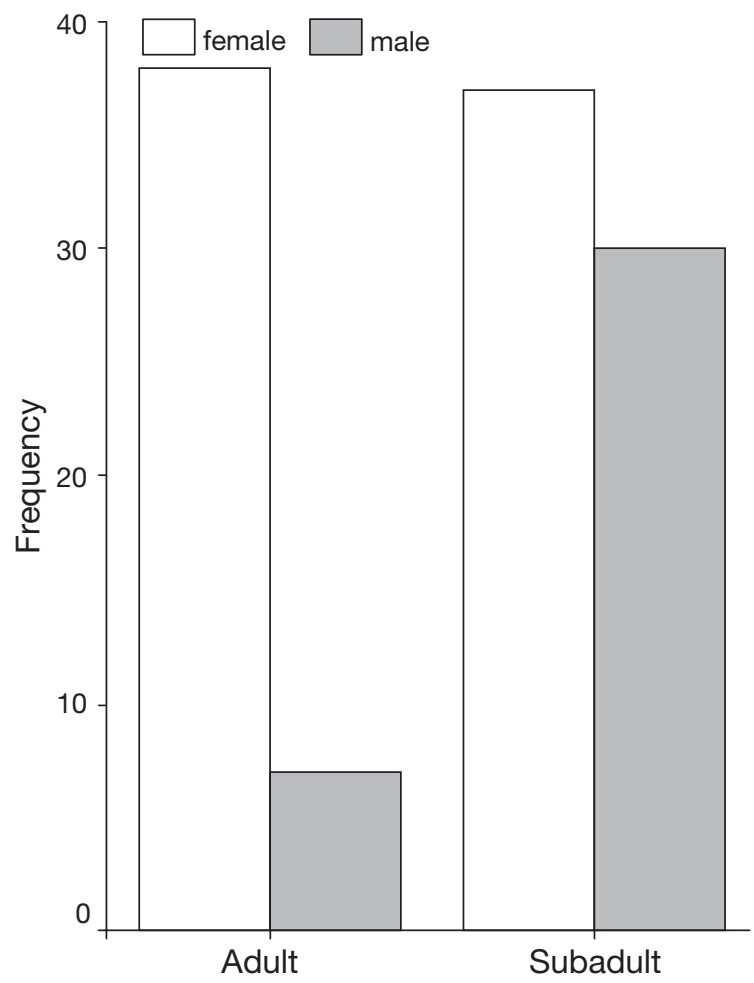

Fig. 2. Phalacrocorax aristotelis. Sex-ratio of adult and immature European shags $(n=122)$ found dead after the Prestige oil spill and collected along the coast of Galicia (NW Spain) 

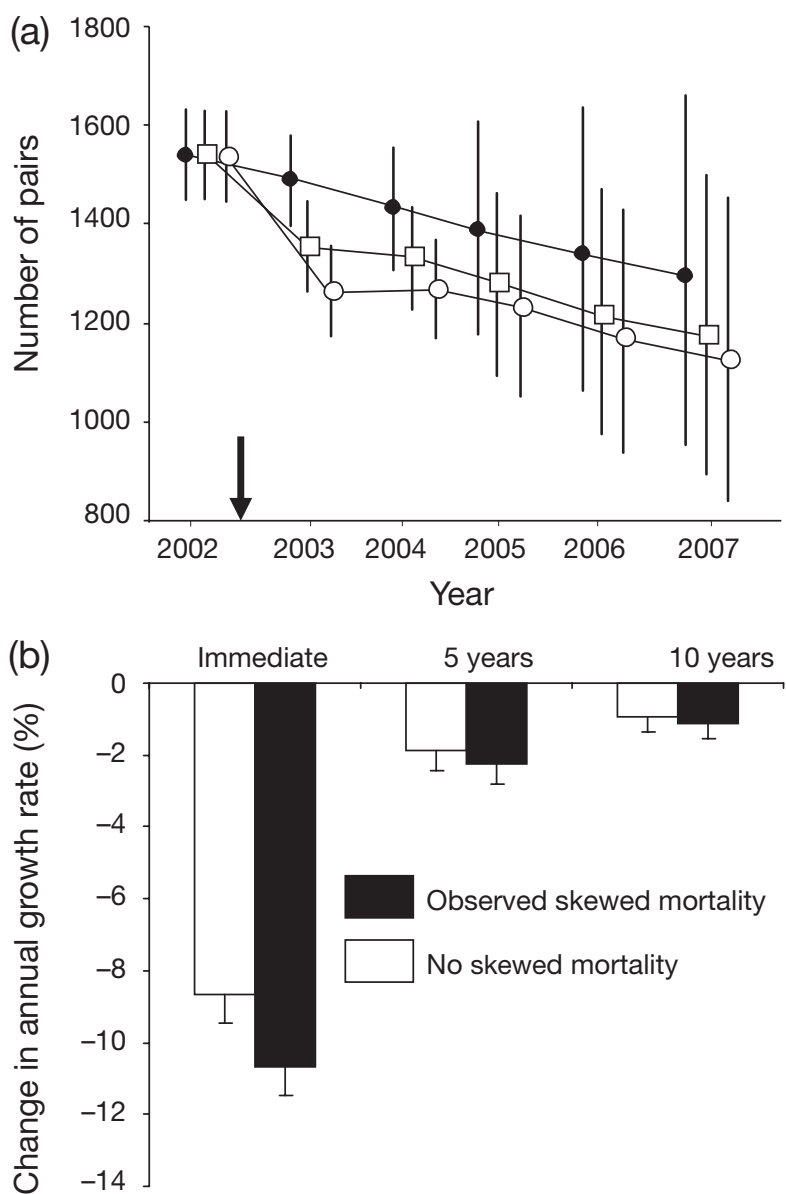

Fig. 3. Phalacrocorax aristotelis. Simulated Monte Carlo population dynamics of European shag for the population of Rías Bajas after the Prestige oil spill. (a) Population trajectories under 3 different scenarios: with pre-spill dynamics and no mortality $(\bullet)$; with the estimated differential mortality by age and sex (O); and with the estimated differential mortality by age, but assuming no sex-skewed mortality ( $\square$ ). Error bars represent $95 \%$ of simulated population values for each time step. (b) Effects of mortality in annual population growth rates with respect to pre-spill dynamics

be reduced by $0.4 \%$ in the 5 yr following the oil spill, and by $0.2 \%$ in the next $10 \mathrm{yr}$, compared with models assuming no skewed mortality (Fig. 3).

\section{DISCUSSION}

European shags Phalacrocorax aristotelis are sporadically affected by wrecks typically caused by outbreaks of poisoning shellfish (Coulson et al. 1968) or long periods of adverse weather conditions leading to food shortages (Aebischer 1993, Harris et al. 1998) of their main prey, sandeels (Harris \& Wanless 1991). However, massive negative effects caused by oil spills have also been reported for this species, here too with a sex-ratio of corpses skewed towards females (Calvo \& Bolton 1997). Female-biased mortality after the Braer oil spill (op. cit.) was attributed to a higher susceptibility of females to adverse effects of the spillage by wintering closer inshore than males.

The female skew in adult shag mortality detected during the Prestige oil spill was probably caused by the earlier arrival of males to colonies (i.e. protandrous arrival) to occupy and defend the best territories to gain access to multiple females (Morbey \& Ydenberg 2001). During winter, male shags, but not females, roost in breeding areas (Cramp \& Simmons 1977). Sex-differences in colony occupation are common in seabirds. For example in herring gulls Larus argentatus, females leave the colony during the non-breeding season, but males remain in the area surrounding the colony throughout the year (Coulson \& Butterfield 1986). This is a typical behaviour in the ideal despotic model of breeding habitat selection shown by male shags (Graves et al. 1993, Aebischer et al. 1995). By the time the spillage took place (November 2002) shags at sea were most likely females, since laying typically takes place in February in the study area (A. Velando unpubl. data) and males were already at breeding places. Similarly, the large number of immature corpses and their 1:1 sex-ratio is probably explained by the fact that immature birds were not defending territories at colonies.

The result of the female skewed mortality could be a deficit in mates with whom males could reproduce and hence a decrease in offspring production (i.e. a decrease in reproductive success at population level). In fact if the oil spill had happened some months earlier the effect could have been much worse since both male and female adult birds would have been at sea. Hence, a sex-related behaviour may be behind a differential level of mortality in this seabird species and in many others. Simulation models suggest that, when female-skewed mortality occurs, a large decrease in breeding numbers is expected, because unmated males can defer breeding, and this may in part explain the considerable decline observed in oiled colonies after oil spills (Velando et al. 2005a,b). This effect was also recorded in Shetland (Scotland), where some kittiwakes Rissa tridactyla did not breed for some years following the Braer oil spill (Walton et al. 1997). Hence, we suggest that unmated adults, owing to skewed sexratios in mortality, could be the mechanism by which oil spills reduce the effective number of breeding pairs beyond that expected when taking into account only the number of birds killed. This fact has been overlooked in the literature.

Although negative demographic effects will probably be short-lived in our study population, sublethal exposure to oil may result in continued poor body con- 
dition, and reduced reproduction and survival of shags in the long term. This species is an inshore and coastal feeder, and is resident throughout the year, and so has increased opportunities for exposure as long as the oil remains in their foraging areas. In Prince William Sound, Alaska, pigeon guillemots Cepphus columba showed unequivocal toxic signs of oil exposure $10 \mathrm{yr}$ after the Exxon Valdez disaster (Golet et al. 2002). Since many seabird species show sexual differences in their choice of foraging locations and diving depths (review in Lewis et al. 2002), sex-specific sublethal effects should be expected. Shags and cormorants show marked sexual differences in foraging depths and food resources (e.g. Casaux et al. 2001). Thus, in addition to sex-specific mortality, sexual differences in oil exposure in their foraging areas could be affecting the population dynamics and constrain the recovery of shags in oil-affected colonies. There is a risk of underestimating the impact of oil pollution on seabirds by overlooking the demographic effects of sex-specific direct mortality and chronic exposures.

Further, considering that during the last decade the local shag population showed an overall decline at an annual rate of $5 \%$, attributed to elevated adult mortality in gill-nets (Velando \& Freire 2002), the future recovery of local colonies could be jeopardized owing to continuous exposure to oil through food webs and reduced food availability (see Velando et al. 2005b).

Acknowledgements. We are grateful to P. Sierra, A. Montesinos, J. M. Lorenzo, L. Jover and X. Ruiz for logistic support during laboratory work. This study would not have been possible without the anonymous work of a large number of volunteers who collected shag corpses in the field. We are grateful to all of them. Funds were partially provided by the Spanish Ministry of Science (grant ref. VEM2003-20052).

\section{LITERATURE CITED}

Aebischer NJ (1993) Immediate and delayed effects of a gale in late spring on the breeding of the shag Phalacrocorax aristotelis. Ibis 135:225-232

Aebischer NJ, Potts GR, Coulson JC (1995) Site and mate fidelity of Shags Phalacrocorax aristotelis at two British colonies. Ibis 137:19-28

Brook BW, Burgman MA, Frankham R (2000) Differences and congruencies between PVA packages: the importance of sex ratio for predictions of extinction risk conservation ecology 4, 6. Available at: www.consecol.org/vol4/iss1/ art6/

Camphuysen K, Heubeck M, Cox SL, Bao R, Humple D, Abraham C, Sandoval A (2002) The Prestige oil spill in Spain. Atl Seabirds 4:129-138

Caughley G (1977) Analysis of vertebrate populations. Blackburn Press, Caldwell, NJ

Casaux X, Favero M, Silva P, Baroni A (2001) Sex difference in diving depths and diet of Antarctic shags at the South Shetland Islands. J Field Ornithol 72:22-29
Caswell H (2001) Matrix population models. Sinauer Publishers, Sunderland, MA

Coulson JC, Butterfield J (1986) Studies on a colony of colour ringed herring gulls Larus argentatus: 2. Colony occupation and feeding outside the breeding season. Bird Study 33:55-59

Coulson JC, Potts GR, Deans IR, Fraser SM (1968) Exceptional mortality of shags and other seabirds caused by a paralytic shellfish poison. Br Birds 61:391-404

Cramp S, Simmons KEL (1977) Handbook of the birds of Europe, the Middle East and North Africa I. Oxford University Press, Oxford

Engen S, Lande R, Saether BE (2003) Demographic stochasticity and Allee effects in populations with two sexes. Ecology 84:2378-2386

Forero MG, González-Solís J, Hobson KA, Donázar JA, Bertellotti M, Blanco G, Bortolotti, GR (2005) Stable isotopes reveal trophic segregation by sex and age in the southern giant petrel in two different food webs. Mar Ecol Prog Ser 296:107-113

García L, Viada C, Moreno-Opo R, Carboneras C, Alcalde A, González F (2003) Impacto de la marea negra del Prestige sobre las aves marinas. SEO/BirdLife, Madrid

García-Pérez JD (2003) Early socio-political and environmental consequences of the Prestige Oil Spill in Galicia. Disasters 27:207-223

Golet $\mathrm{GH}$, Seiser PE, McGuire AD, Roby DD and 6 others (2002) Long-term direct and indirect effects of the 'Exxon Valdez' oil spill on pigeon guillemots in Prince William Sound, Alaska. Mar Ecol Prog Ser 241:287-304

Graves J, Ortega-Ruano J, Slater PJB (1993) Extra-pair copulations and paternity in shags: do females choose better males? Proc R Soc Lond B 253:3-7

Harris MP, Wanless S (1991) The importance of the lesser sandeel Ammodytes marinus in the diet of the shag Phalacrocorax aristotelis. Ornis Scand 22:375-382

Harris MP, Wanless S, Elston DA (1998) Age-related effects of a nonbreeding event and a winter wreck on the survival of shags Phalacrocorax aristotelis. Ibis 140:310-314

Heubeck M, Camphuysen CJ, Bao R, Humple D, Sandoval A, Cadiou B, Bräger S, Thomas T (2003) Assessing the impact of major oil spills on seabird populations. Mar Pollut Bull 46:900-902

Legendre S, Clobert J, Moller AP, Sorci G (1999) Demographic stochasticity and social mating system in the process of extinction of small populations: the case of passerines introduced to New Zealand. Am Nat 153:449-463

Lewis S, Benvenuti S, Dall'Antonia L, Griffiths R, Money L, Sherratt TN, Wanless S, Hamer KC (2002) Sex-specific foraging behaviour in a monomorphic seabird. Proc R Soc Lond B 269:1687-1693

Martínez-Abraín A, Oro D, Jiménez J (2001) The dynamics of a colonization event in the European shag: the roles of immigration and demographic stochasticity. Waterbirds 24:97-102

Morbey YE, Ydenberg RC (2001) Protandrous arrival timing to breeding areas: a review. Ecol Lett 4:663-673

Potts GR, Coulson JC, Deans IR (1980) Population dynamics and breeding success of the shag, Phalacrocorax aristotelis, on the Farne Islands, Northumberland. J Anim Ecol 49:465-484

Rice SD, Spies RB, Wolfe DA, Wright BA (1996) Proceedings of the Exxon Valdez oil spill symposium. Am Fish Soc Symp, 18. American Fisheries Society, Bethesda, MD

Stearns SC (1992) The evolution of life histories. Oxford University Press, New York

Velando A, Alvarez D (2004) Cormoran Moñudo, Phalacroco- 
rax aristotelis aristotelis. In: Madroño A, Gonzalez C, Atienza JC (eds) Libro Rojo de las Aves de España. Ministerio de Medio Ambiente-SEO/Birdlife, Madrid, p 60-62

Velando A, Freire J (1999) Intercolony and seasonal differences in the breeding diet of European shags on the Galician coast (NW Spain). Mar Ecol Prog Ser 188:225-236

Velando A, Freire J (2002) Population modelling of European shags (Phalacrocorax aristotelis) at their southern limit: conservation implications. Biol Conserv 107:59-69

Velando A, Docampo F, Alvarez D (1999) The status of the European shag Phalacrocorax aristotelis population on the Atlantic coast of the Iberian Peninsula. Atl Seabirds 1: 105-114

Velando A, Graves J, Ortega-Ruano JE (2002) Sex ratio in relation to timing of breeding, and laying sequence in a dimorphic seabird. Ibis 144:9-16

Editorial responsibility: Otto Kinne (Editor-in-Chief), Oldendorf/Luhe, Germany
Velando A, Alvarez D, Mouriño J, Arcos F, Barros A (2005a) Population trends and reproductive success of the European shag Phalacrocorax aristotelis on the Iberian Peninsula following the Prestige oil spill. J Ornithol 146: $116-120$

Velando A, Munilla I, Leyenda PM (2005b) Short-term indirect effects of the 'Prestige' oil spill on European shags: changes in availability of prey. Mar Ecol Prog Ser 302:263-274

Walton P, Turner CMR, Austin G, Burns MD, Monaghan P (1997) Sub-lethal effects of an oil pollution incident on breeding kittiwakes Rissa tridactyla. Mar Ecol Prog Ser 155:261-268

Weimerskirch H, Jouventin P (1987) Population dynamics of the Wandering albatross Diomedea exulans of the Crozet islands: causes and consequences of the population decline. Oikos 49:315-322

Submitted: October 11, 2005; Accepted: January 24, 2006

Proofs received from author(s): July 10, 2006 